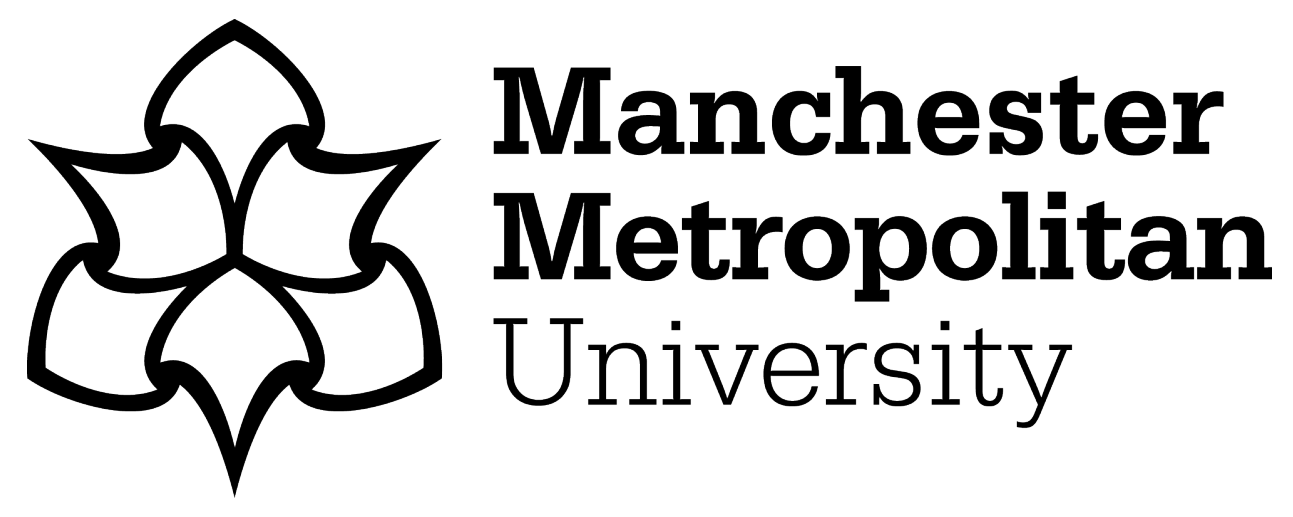

Ravetz, Amanda (2019) On Reverie, Collaboration, and Recovery. Collaborative Anthropologies, 10 (1). pp. 45-66. ISSN 2152-4009

Downloaded from: https://e-space.mmu.ac.uk/622199/

Version: Accepted Version

Publisher: University of Nebraska Press

DOI: https://doi.org/10.1353/cla.2017.0002

Please cite the published version 
Amanda Ravetz,

Abstract: This is a meditation on reverie and collaboration in the context of recovthe rewards of working through thought processes in connection with visual expression. Several narrative moments of my own journey are presented, emphasizing the depth of time it can take to realize ways of becoming writers, artists, anthropologists, people. Coming to know is a long-term commitment, with previous experiences feeding into present and future collaborations. A desire to combine anthropolog-

becoming human in which trust and vulnerability, together with solidarity and gratitude, helped with the digestion of experiences of addiction and recovery. Reverie and collaboration are conceptualized less as a set of techniques and more as a call to disciplines to intersect at crucial points, or, inspired by intimations of "things in themselves," to suspend categorical boundaries.

Keywords: Reverie, recovery, addiction, vulnerability, gratitude, art

I used to feel envious of artists and writers who said that the germ for their work was a tiny fragment of something - a story or an image. These fragments then blossomed into stories, braided creative nonfiction narratives or artworks. I was envious because of the resistance I encountered, in myself, to straying too far from the literal. Strange, because my college education began with a painting degree where imagination was highly 
prized. As a mature student, shifting my attention to social anthropology, I enjoyed mastering rational thought processes alongside documentary filmmaking. I often felt confused though by the way emotional insight was treated as untrustworthy in academia, contaminating even. I adopted some of this skepticism myself where undigested emotion was concerned, but railed against the demotion of personal insight and transformation, thinking it part of the research process and in some way necessary to learning. The exclusion of personal insight seemed to be reflected too in a lack of wandering in academic writing that I searched for since:

... when the mind wanders from its attachment to the specific perceptual reality it makes that transition to psychic being whose reality is known through symbols, the manipulation of which allows the act of insight. ${ }^{1}$

This frustration was offset by observational filmmaking that was part of my postgraduate study, which allowed feeling and the senses into anthropological study, and I gravitated toward examples of film and writing that resonated with experiences in drawing and painting, of the fundamental entanglement of people, places, and things.

In my personal life and sometimes as a filmmaker, mysteriously transformative ways of knowing could happen-akin to what the psychoanalyst Wilfred Bion talked of as knowing by "becoming" (cited in Grotstein 2007). This felt like an antidote to the use of rational explanation, which I slowly realized allowed me to edit feelings, creating an illusion of order, and which I thought of as knowing about things. Over time it became more pressing to bring these two things together: "knowing about" and "knowing by becoming." I idealized this as a collaboration between my two disciplinary backgrounds, art and anthropology. "Knowing by becoming" seemed more obviously aligned to art practice and had a pre-conscious quality; "knowing about" was the imperative that I believed underpinned anthropology. I conceived of their collaboration in a reciprocal way: an exchange entered into, that through joint endeavor leaves one or both sides changed. Yet this definition hid a different way of experiencing collaboration, one of merging with my surroundings in a way that could sometimes lead to an intimation of "things in themselves." Later I would find out that Bion used the letter $O$ to describe a state of this kind: ineffable, intangible, impossible to pin down.

As an art student in my late teens I had read a book by artist and psychoanalyst Marion Milner. On Not Being Able to Paint (Milner 1957) 
described a semi-mystical sensation of liveness that I believed I had also

experienced a few times - being both present and fully attentive to and 2 yet ecstatically dispersed into my surroundings, beyond the surface of my 3 skin. In this state, things were momentarily stripped of their ordinariness, intensified, cut free from everyday sensory references. ${ }^{2}$ Milner's writing related the sensation of liveness to a particular condition that she called reverie. ${ }^{3}$

As an artist, as well as a psychoanalyst, Marion Milner wrote that states of reverie arose while she was drawing and painting, once she had learned how to bear and analyze her painful feelings via free association. She viewed painting and drawing as modes of material manipulation that resemble children's early experiences of psychic reality, mediated through "transitional objects"-babbling, handling favorite toys or pieces of cloth, and so on. The legacy of this play, she suggested, with its deep ties to reverie, was to be found in art processes and products, which were relational in character, sitting somewhere between experiences of self and other. ${ }^{4}$

For a long time I did not mention my own "connective" encounters to anyone. They arrived and left of their own volition and I was secretive about them. Later, as a training visual anthropologist and fieldworker, when these experiences occasionally returned, it took me a long time to grasp that they were not only a side effect of my research activity but also a powerful motivator. Whether filming observationally, drawing, attempting to write ethnography "otherwise," or participating in artistic research, I came to think of them as the medium in which art and anthropology came together. To grasp what this meant I used Milner's definition of reverie: "the kind of concentration that we call 'losing oneself in an activity, something that can be greatly longed for, delighted in, but which does require a safe setting, a setting that will still be there when one emerges again into ordinary self-awareness" (Milner 1987, 81).

My experiences of reverie had several things in common. They appeared to require

a generative, bounded, "safe-enough" space;

a degree of trust and collaborative and transformative exchange with others-whether human persons or live materials;

the ability to be vulnerable-that is, wholehearted in the knowledge that this might be painful or end in failure;

recognition and containment of frustration or emotional pain;

4

5

6

7

8

9

10

11

12

13

14

15

16

17

18

19

20

21

22

23

24

25

26

27

28

29

30

31

32

33

34

35

36

37

38 
the presence of improvization and "not-knowing"

forms of making or moving activity—drawing, filming, driving, sewing.

Reverie also appeared inherently relational, despite a commonplace understanding of it and its close cousin, daydreaming, as solipsistic, internal, and hidden — and for me it involved social and therefore ecological relations. ${ }^{5}$

\section{Between Art and Anthropology}

My PhD fieldwork in the late 199os took place in the northern English town where I lived at the time. It explored ways of seeing and knowing. I moved among four different sites: a social housing estate, a hill farm, a factory, and the annual agricultural show.

Much of my fieldwork used an observational cinematic approach, but on the housing estate the kind of trust needed for this form of immersive filmmaking was hard to establish, and I often found myself giving people lifts in my car while they used the camera. The car emerged unexpectedly as an enabler of shared confidences-a bounded, relatively trustful, contingent space where emotions and feelings could be shared and negotiated while in movement. All kinds of conversations only happened in the car. Journeys to other towns, or to prison to visit partners and ex-partners, prompted instances of dreamlike exchange and vulnerable disclosure.

Several years later, as I was reviewing some of this video material with a small group of artists, ${ }^{6}$ it was pointed out that had I been working as a contemporary artist, rather than an anthropologist, I might have viewed the car journeys in the context of social art practice, understanding this as an artist-run "taxi service" perhaps, and the basis for a performance piece, an artist video, or gallery show.

I was intrigued by the similarities and differences between my anthropologically inflected ways of being a researcher and these artists' ideas. I had moved into anthropology because I did not know how to connect painting to a social practice, and because despite my being in the thrall of the reverie-like states, their mystical connotations embarrassed me. Now a desire began to form to "think like an anthropologist and to imagine like an artist." 
In 2004, nearly three years after finishing my $\mathrm{PhD}$, with a brief sojourn teaching anthropological filmmaking, I reentered art school, this time as a research fellow with acknowledged ties to both art and visual anthropology. Along with my outward focus on visual and aesthetic ethnography, my emerging aim was to intercept and consider my social science rationalism through a different, more openly experiential kind of knowing.

My research focused on the theory and practice of observational cinema but also included attempts to write more personally alongside some modest experiments in drawing. I was unsure of my disciplinary and academic affiliation, feeling myself to be in an "inbetween" space, and for a long time this bothered me. Should I resume my earlier art (student) training and engage with questions of form and contemporary art theory, remaking myself as a socially engaged artist? Or pursue social and visual anthropology with more passion, keeping up with all the current debates and practices developing across art and anthropology? I seemed unable to do other than occupy the liminal space between them. If I got too close to one or the other discipline, the fantasy of reverie would desert me.

\section{Tapping into Reverie}

To understand more about reverie, and what could induce it to happen, I began to look for references to research that connected with my experiences of filmmaking, painting, and drawing more closely: for example, Jean Rouch's ciné-transe and texts by Marion Milner, Donald Winnicott, Samuel Ogden, Wilfred Bion, and Gaston Bachelard about reverie, psychoanalysis, and creativity.

The investigations they described-what reverie was, why it mattered, and how to achieve it-gave clues to my unwillingness to affiliate too strongly with one discipline or another. They suggested that reverie had to be pursued tangentially, with something other than a directly sensory or empirical approach. As when seeing something from the corner of your eye, or wandering through a landscape without knowing why you were there or where you were going, the state could vanish easily under the pressure of goal setting, disciplinary norms, and analytical thinking. Reverie needed a safe space that would be there when one emerged again. For me this space occurred between art and anthropology.

Remembering that in the past, I had found drawing could foster a sideways perception, I began drawing occasionally alongside my read- 

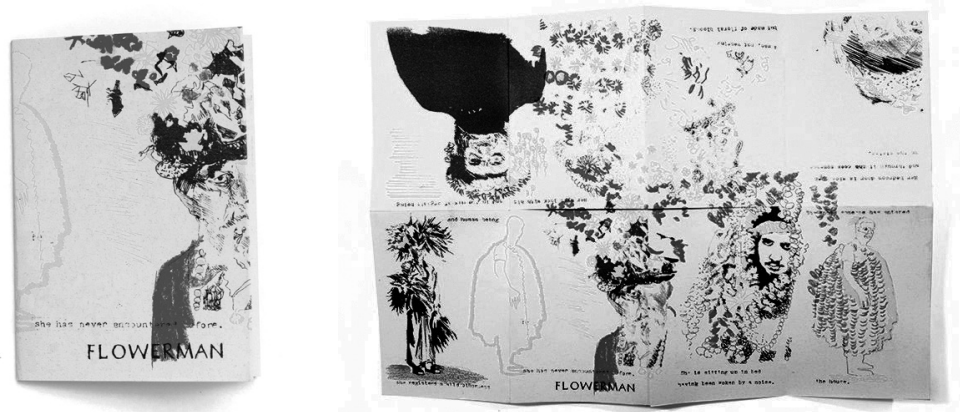

Fig. 1a and 1 b. Flowerman beak book by Amanda Ravetz. Photographs of the book by Jon Barraclough.

ing and writing-doodles, observational sketches_playing with color and form as a way to deflect my habitual "straight line" thinking. I read poetry and creative nonfiction in addition to academic papers. I taught academic writing to art and design students, introducing them to creative nonfiction with the idea that the resistance they were experiencing to theory might be lessened if their academic voices could converse with their artistic sensibilities. As I supplemented my theoretical diet with emotional and poetic material, fragments of images and stories arose, among them a powerful reminder of the encounter with things in themselves that reverie could produce. ${ }^{7}$

I had a night time dream in which a man made completely of floral blooms climbed the stairs of my house, and still in the dream, I woke up startled and looked directly into his eyes. There I saw something wilder, more "other" than I had ever before encountered.

I made two things as a result: a small fold-up book of drawings with minimal text narrating my dream (fig. 1a) and a prose piece about a woman returning to a childhood house intertwined with a meditation on reverie (fig.1b). ${ }^{8}$ Although modest, making these things broke through my self-censorship of what I could allow myself to speak of academically.

\section{Collaboration through Drawing}

For a while my active attempts to nurture reverie rather than waiting for it to appear had involved me in small collaborations with my inner pro- 

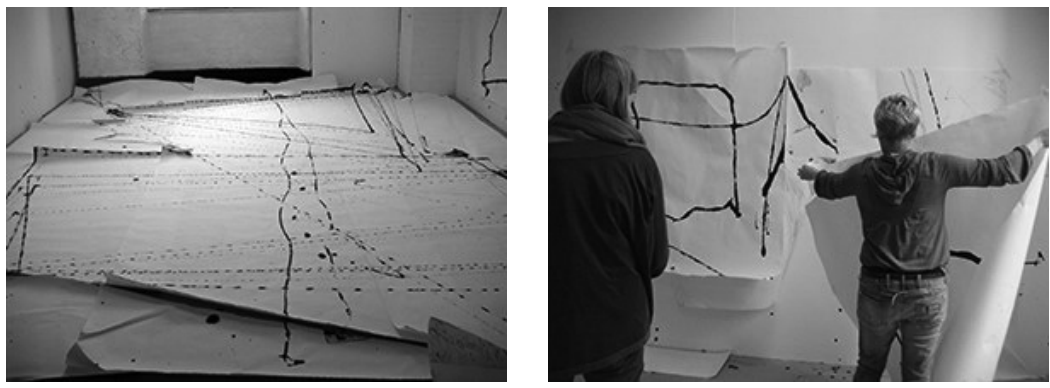

Fig. 2a and 2b. Day 1, April 2014. Photographs by Amanda Ravetz.

cesses and outer materials. I decided to expand this with an experiment in 2012 called Sipping Water. ${ }^{9}$ Could drawing provide the enabling circumstances for others' experiences of reverie? I wrote a score inspired by the investigations of two colleagues, Anne Douglas and Kathleen Coessens, into Allan Kaprow's scores, and for eight weeks the three of us drew "together" in separate locations, recording and later comparing our reactions and reflections. The conditions the score set up, which included the slow sipping of water, were designed to encourage an intense mode of attention, not focused on the outside world, nor totally on the inside world either, bringing to the surface feelings, with the potential for these to be digested. The experiment, which I understood as a collaboration between us and the materials, and with one another, confirmed to me that reverie can be enabled and reflected upon through drawing. ${ }^{10}$

Two years later I was able to test this further during an intensive threeday workshop when Anne Douglas, Kate Genever, and I drew together in 28 the same physical space while sharing ongoing reflections. ${ }^{11}$ By slowing down our process we found drawing enabled us to hold open a space for 30 something unplanned and unexpected to happen (Douglas et al. 2014;

Pahl et al. 2017). In this slower space, by valuing the here and now and 32 staying with small beginnings, we were helped to reflect on an emerging process between us. There were harmonious moments but also wobbly moments of disengagement or uncertainty. The subtly agonistic elements of our interaction were tangible. We noticed small changes of atmosphere, our passing senses of frustration and disillusionment. Drawing together made more palpable the various qualities of reverie. 


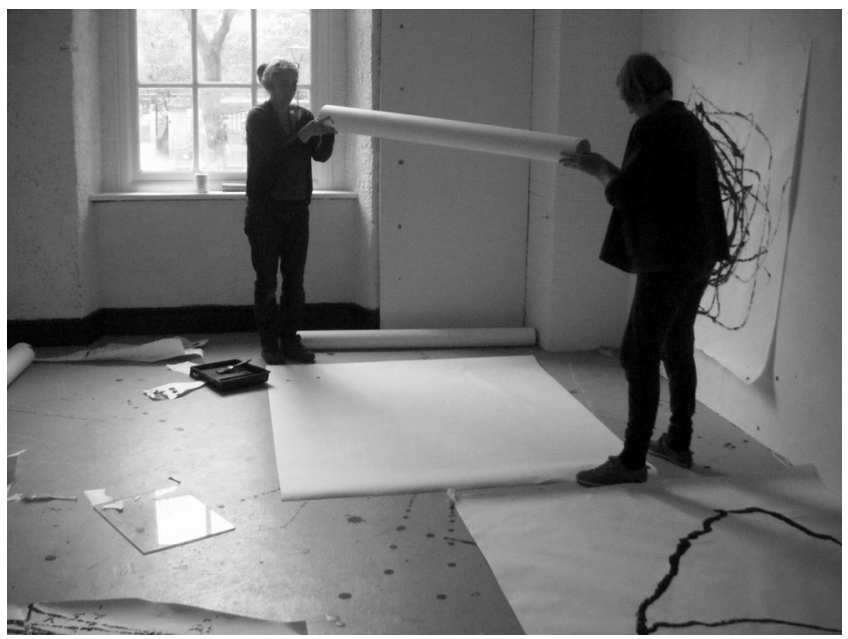

Fig. 3. Day 2, April 2014. Photograph by Kate Genever.

Later we published a paper in a special issue of the Journal of Arts and Communities on what we had found out. ${ }^{12}$ We suggested that drawing together can open new approaches to questions of community. ${ }^{13} \mathrm{We}$ argued for a rethinking of participation beyond its common concerns with improvement to access, techniques, conviviality, and modes of data elicitation. While community artists are often valued for the access they allow to those routinely excluded from the arts, our collaboration led us to argue, following Nancy (1991), that community is an immanent condition, not something to be manufactured or operationalized. Nancy's writings theorize a state of "being-with," into which all humans are born (2013, 11), not an original state that has been lost and needs to be refound. The latter, he argues, carries with it the dangerous desire for closed, undivided social identities and imaginaries. Following this argument, we proposed drawing together not as a technique through which to operationalize community but as a way to find a form to come, to which participation is integral.

\section{Into Recovery}

The small-scale drawing experiments helped to distill questions about reverie, its enabling conditions, and its capacity for transformation. 
They also crystallized an image for me of two arms, which cannot act together while unaware of each other. It was an image from my own imaginings and the conditions around me. Social anthropology is committed to disciplined conceptual thinking and rigorous analysis of structures and experiences, including the numinous experiences of others. Contemporary art supports experiential, critical, and often transgressive engagement by artists with contemporary issues. To connect these two impulses beyond operational models of collaboration might need something of the slow, trusting, and painful conditions known to be engendered by reverie. Such reflections underlay a new research project in 2015 with a group of people in recovery from addiction.

Addiction to alcohol was something I had an aversion to, having grown up with an alcoholic father. But through a conversation with Melanie Manchot about her work Twelve, ${ }^{14}$ I met the curator Mark Prest, ${ }^{15}$ and realizing we were both interested in liminality, we established a research partnership, together with a small group of people in recovery, which we entitled Wonderland: the art of becoming human. ${ }^{16}$

The research was co-produced with several recovery organizations and the artist Cristina Nuñez, who led two intensive three-day workshops during the project. ${ }^{17}$ The partners, all in recovery themselves, took part to further their own recovery journeys while also recruiting additional participants. My own motivation was to ask whether reverie could be enabled by an art form other than drawing, in the context of recovery. The research also allowed me to approach a topic that had a strong emotional charge for me.

Ten participants came into Manchester School of Art at regular intervals over a period of several months. Artist Cristina Nuñez, herself in long-term recovery from heroin addiction, invited us into her wellestablished methodology and practice of photographic self-portraiture. ${ }^{18}$ In between workshops participants followed additional exercises designed by Cristina to stimulate emotional and photographic learning. ${ }^{19}$ Images were reviewed in the workshops and, with help from the artist and the group, edited by the participants into self-authored "artists' books."

The project was based on a "recoverist" model of addiction and recovery, 
published as the Recoverist Manifesto. ${ }^{20}$ Recoverism seeks to reframe and humanize the lived experience of substance misuse or mental distress away from biomedical models, pathologies, and criminalization. In this context the emergence of reverie during the project played a powerful role. ${ }^{21}$ When people stood on their own having been asked by Cristina to act out and then attempt to step into an emotion, with only the stills and video cameras, the "altered" state of consciousness while performing to the camera was tangible in the images. A film made during these sessions shows the emotional bodily responses of participants in front of the camera and records their subjective feelings during group conversations. ${ }^{22}$ At points during group reviews of the images, when participants shared and supported one another in naming emotions and reflecting on feelings, reverie, as a state of being safely lost in an activity, was palpable. People reported too that taking photographs in favorite and feared environments, of family pets, and with members of their families, felt unusually intense, for some transforming their understandings of themselves and their relations.

In conversations, peer-to-peer interviews, the closed Facebook group, and evaluation documents, participants and partners also reported strong feelings of group connection.

The six participants who stayed until the end of the project said they felt more connected and self-accepting by the end of the project, and more involved in photography. Two younger women said it had deeply changed how they dealt with emotions and feelings. They were able to talk more about their feelings and had started to use photography with their children to help them process emotions. One participant explained that the photographic activity got into her body, her skin, and onto the insides of her mouth, making her think about all the ways she had used words to lie to herself and others in the past. She said that speaking with her body instead of with words meant she couldn't deceive herself and others so easily. Now that her body had spoken, she said she could come back to words and say things in new ways. ${ }^{23}$ Another participant spoke of being part of the group as something alienating to begin with but then freeing.

How I felt this week-I honestly wanted to bow out of this as I felt I didn't get it, you are all more educated than me, I'm common, I'm not needed or able to give good comments on topics $\mathrm{X}$ and truth be told, the bond I felt with you all kept me going and I feel truly connected 


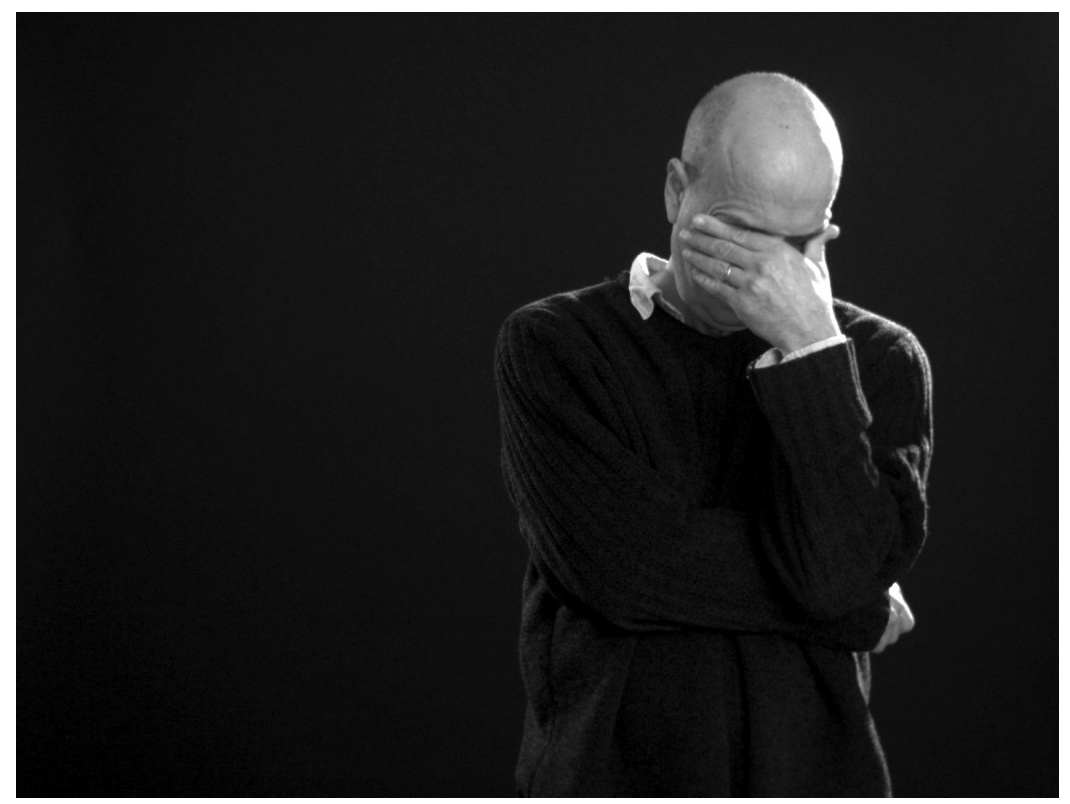

Fig. 4. Video still, Wonderland: the art of becoming human.

and empowered by the work and honesty and friendship we have built

$\mathrm{X} \vee$ to you all $\mathrm{x}$ even opened up a conversation with my mum about

it, and she said that's one thing she regrets is not pushing me to feel

the fear and doing it anyway $\mathrm{X}$ so from her she thanks you all for

Much of the process involved confronting painful feelings. The artists' books for example are emotionally raw, as noted by one commentator. ${ }^{24}$

The challenge of working with emotions and feelings might explain in part the drop-off rate between the first and the second workshop. The first workshop was attended by 100 percent of participants for all three days. Four people (40 percent) did not return for the second workshop. Of these, two said it was because of illness (which might have been related to the demands of the first workshop, though this was not established). One said the family roots aspect of the homework exercises was too painful. The last wrote of the value of having come this far:

... hope your wonderland is going well sorry I couldn't see it through 
through with that but after I went and did 100\% at the

on stage and I had similar fear of people looking at us and conquered it so you have helped me you have my permit ion to use anything you have of me and you don't go cutting me out ha ha good luck $\mathrm{xx}$

During one of the evaluation sessions at the end of the project I suggested to the group that dropping out could be interpreted as a critique of the project. A couple of people responded by saying that learning to express your limits and say "no" is an important aspect of the recovery process. Others admitted to having had what they imagined were similar moments of intense struggle and having endured and overcome these only because of other group members, who had lived through comparable things and therefore understood the depth of feeling being endured (fig. 4). The success of the process rested on the ability of the group as a whole to support, contain, and help transform substantial levels of pain and frustration, in a co-produced safe setting.

Along with pain and fragmentation, there were also references made to gratitude. One participant talked of recovery as "a beam of light I've gone towards." He described how before his recovery journey got underway he had sat in a park and hurt himself with keys for about an hour, and nobody had stopped him, because "Who cared?" Now, on the other side of his active addiction he believed, "You've got to be thankful for the recovery to like say, this is your chance here now, take it." Others echoed this sentiment.

An attitude of gratitude is explicitly cultivated within social models of recovery. As one recovery website says:

When people are grateful for what they have, they will experience a great deal of happiness in their life. When the individual is constantly lamenting their lot, it will be impossible for them to find peace of mind. Gratitude is not about what people have or do not have. ${ }^{25}$

Gratitude echoes "asset-based" attitudes to recovery (these are our abilities), rather than a deficit-based approach (everything that is wrong with the addict), the latter framing treatment-based approaches to addiction in the UK until recently. Asset-based approaches have attracted criticism, however, for potentially deflecting attention away from links between socioeconomic conditions and health outcomes. Lynne Friedli (2012), for example, points out that as material inequalities have grown, 
non-material reasons given for poor health have proliferated so that too often,

psycho-social factors are abstracted from the material realities of people's lives and function as an alternative to addressing questions of economic power and privilege and their relationship to the distribution of health. The growing influence of salutogenesis and asset-based approaches is one example of this trend.

While recoverism clearly demonstrates an asset-based approach, dedicated to reflecting recoverists' strengths, it resists the abstraction Friedli picks up on, by actively supporting a socioeconomic determinants of health model. ${ }^{26}$ Recoverists would argue that gratitude in and of itself does not preclude links being made between economic power and the distribution of health.

Robin Wall Kimmerer, botanist, environmental activist, and Potawatomi advocate of traditional knowledge, communicates her experiences of the personhood of the animal and plant world in ways highly suggestive of both reverie and gratitude, evoking what Dan Rose, in a review of a book about mysticism and psychoanalysis, calls "the ability of surrendering to the unknown and allowing some inner core of the individual to be touched by the effects of living." ${ }^{27}$ Reflecting the talk of gratitude during Wonderland, Kimmerer (2013) argues that it is what we 21 need most in the world. Gratitude not from the head, but as a shift of positionality from the experience of the individual whose self ends at the skin's edge, to one of connection and unity. Kimmerer comes back repeatedly to the radical, political potential of being grateful for existence, 25 simultaneously providing detailed critique and powerful testimony of 26 colonial decimation of Native American peoples, lands, and lifeways. She argues that within an economy that tells us, constantly, that we are empty and should consume more, it is a radical act to feel the plentitude of what 29 life at its most basic and fundamental form gives us.

Kimmerer is an advocate of land restoration-or understood in another way, the recovery of our relationship with land. Her message has 32 many parallels to the discourses circulating during Wonderland both by 34 the artist and between the participants: not to take, but to work through 35 relationship and to see what is offered; not to explain or translate or con36 ceptualize, but to learn by becoming the thing you want to understand; 
not to be informed and in turn to inform, but to be moved and to move others in turn.

\section{Reverie as a Kind of Collaboration}

Moving from experiences of reverie at art school and in daily life, into fieldwork, and on to experiments with drawing and recovery, I now understand reverie and collaboration as stranded around one another. If reverie is an "otherwise" form of attention, a particular quality of concentration, a mode of digesting emotions and feelings that requires the surrender of goal-oriented ambitions, it is also a deep form of exchange with one's social-ecological surroundings.

At a theoretical level, seeing reverie and collaboration in this way differs significantly from a conception that views collaboration as a way to deliver theoretical and conceptual change, or to bring about psychosocial transformation, evidenced through the capture of certain qualitative and quantitative data. Reverie does not leave easily evidenced "outward" traces. It is hard to describe, and almost impossible to bring to heel. It is mysterious and potentially volatile. As an observational filmmaker experiencing reverie, I had a sense of dissolving borders between self and world, and strong intimations of "things in themselves"; in Kant's term noumenon, and in Bion's $O^{28}$ :

that which is the ultimate reality represented by terms such as ultimate reality, absolute truth, the godhead, the infinite, the thing-in-itself. $\left(\right.$ Bion 1970, 26) ${ }^{29}$

Experiences of this kind are not so distant from encounters with the sacred, parsed by Kay Milton (2002) in reference to Bateson's ideas as to do with wholeness and unity, sweeping away explanations rooted in rational thinking. This is difficult to square with conceptions of collaboration in research underpinned by transparent, replicable methods, empirical evidence, and answers that add to a shared corpus of knowledge. This is not to say these principles and methods have to be abandoned in research with and about reverie, nor is it to discount thoroughness (aka rigor) and trustworthiness. I adhere to the need for these. Rather it is to suggest that method must always make contact with that which it wishes to understand. Reverie demands to be made contact with yet left tantalizingly on the edges of knowledge in ways that continuously go

58 - COLLABORATIVE ANTHROPOLOGIES • 10:1-2 • FALL-SPRING 2017-18 
on challenging what is familiar to us. Despite the fact that "staying with something unknown and not trying to make it known is unsettling and risky," it is also "the only way for learning to occur," according to Ang and Gatt (this volume).

Within psychoanalysis, a field explicitly engaged with reverie, Bion theorizes it as the state needed by a primary carer to assist an infant's processing of raw sense data-Grotstein further explains this using the analogy of renal dialysis; that is, as necessary for survival (2007, 45; 157; 298). Without a carer's reverie the infant is vulnerable to uncontainable pain. Over time healthy children learn to use reverie themselves to digest sense data. But if they are ill-equipped to do this, difficult feelings are likely to be blocked off from everyday consciousness, while still exerting their power. For Bion, the work of the analyst and the analysand takes its lead from this primary dyad. As with the infant's carer, the analyst's role is to "dream" and interpret the analysand's "un-thought" frustrations and emotions.

In ways that support the connections made between reverie and artistic endeavor, Bion sees reverie as the core procedure of the aesthetic process, akin to Keats's negative capability-the ability to stay in a state of uncomfortable uncertainty without irritable frustration. Reverie carries with it the potential to liberate those who experience it from all things handed down-from models and rules, accepted canons of science and art. Bion believed that any new thought is felt by the psyche as potentially disruptive and shattering, but the ability to tolerate this level of upheaval results in new growth. It is this capacity for reverie that allows human beings to create, to dissolve ways of seeing and being, to endure states of fragmentation, and to take this material and use it to make new connections. This is often a painful process and as such is dependent on an individual's capacity to withstand anxiety, doubt, and fragmentation.

I thought about the kinds of contact various methods institute when reading the introduction to the book Addiction Trajectories (Raikhel and Garriot 2013). It gave me a jarring reminder of being disciplined by a field and its favored language, rather than being helped into a new collaborative relationship with the people, places, and things:

As we have suggested, addiction offers a particularly fruitful area for the advancement of anthropological theory today because it is a privileged site where individual experiences of desire, pleasure, and suffering; the expertise of professionals in medicine, psychotherapy, and 
the law; and the regulatory ambitions of the state intersect in ways that blur the distinction between the vital and the lethal, the normal and the pathological, illness and treatment (emphasis added).

In a way, this is a statement about a collaboration between researchers and a group of people, a statement that in talking to the discipline, has to promise that if transformation occurs, it will be in areas already sanctioned. The intention of this book is I believe one of critical rigor together with solidarity with those living with addiction. But this language does not communicate what addiction means to those who live with it or the possibilities for all involved to grow and experience change through solidarity and connection. It speaks rather of the judicious choice of topic for research careers and the maintenance of disciplinary territory.

Similarly, in contemporary art, avant-garde notions of transgression flourish, but reverie and related phenomena with their mystical aura easily appear outlandish, particularly in a research context: mad, or religious (and mad), or too close to psychology or therapy. It could be argued that the growing popularity of the use of biomedical measures of physiological responses in collaborative projects across art, design, and science is at times a defense against the "shame" of entertaining unmeasurable and unnamable feelings. But there is also an equal and opposite problem, that the particularity of reverie is perhaps being subsumed within the discourses of "not-knowing" that are currently so popular within art and design. I am not discrediting either of these approaches, which are used for good reason, but in my view neither could bring to the surface nor theorize reverie's painful, fragmentary, and destructive characteristics, its digestive capacity, or its surprising association with gratitude. It might turn out, for example, that approached as a physiological state, reverie changes brain frequencies in favorable ways, as has been claimed for meditation and flow; but consideration of the existential and relational value of reverie should prompt an equally important conversation about the forms rigor-which in artistic research I would parse as thorough digestion and trustworthiness-can take in academic research.

\section{Collaboration, Reverie, and Recovery: Some Reflections}

Where does this narrative leave questions of reverie and collaboration? What does it suggest about the possibilities for bringing together know- 
ing about and knowing by becoming in academic research culture? What does recovery ask of our academic institutions?

I set out to write this essay in a register tuned to my own and others' lived experiences of reverie by making digestive and associative connections between my materials. To do this I have had to put aside anxieties that by not filling this space up with copious qualifications, citations, and theoretical explanations I would risk invalidation through lack of explicit academic rigor. My rationale was that different ways of writing and thinking are sometimes required to address existing assumptions and to arrive at new questions and propositions.

My growing sense is that many anthropologists absorbed in durational fieldwork, and most artists in moments of being productively lost in their practice, have experiences of reverie-it does not equate to uninterrupted flow but, as we have seen, can involve fragmentation, rupture, and pain. If this is so, then it is as urgent to understand this shared impulse toward knowing by becoming as it is to know "more" about anything.

In the same way that Kimmerer suggests gratitude as a radical corrective to consumption - and paradoxically loss-I propose reverie as a radical corrective to extractive research performed on people, things, culture-including the effects this mode of research has on the researchers themselves. Able to enter reverie, the dreamer is vulnerable and receptive, open to temporary fragmentation, mindful of the many different ways in which meaning and communication happen. Far from being the preserve of romantics and utopians, reverie is ubiquitous, commonplace, something for which human persons have a willing propensity.

Bion insisted that psychic reality and reverie have to eschew the sensory world purposefully-which I take to mean to leave hold of the overly empirical and literal world so as to dream up an equally emphatic, shared but less literal reality. Milner found as long ago as the 1930s that children's capacity for creativity, for psychic renewal, depended on a safe space that made it possible for their grip on one reality to be let go in order for them to feel more fully alive through contact with another (1938). But some of the children she worked with found it too hard to leave the known world of conformity in order to experience psychic recovery. In Milner's self-experimentation, her own sense of liveness and creativity depended fundamentally on her growing capacity for reverie as an exchange, a collaboration with all that lay within and around her (1957). In an analogous way, reverie challenges models of collaboration within research culture 
when these insist that findings are only valid when based on narrowly interpreted forms of empirical evidence.

Given the imperative for change that exists in all collaboration, everyone involved is open to experiences of disruption and possibly pain and fragmentation. Existing studies, hypotheses, and experiments suggest that reverie, and the recovery that can ensue from it, require safe spaces into which the vitalizing moment of recovery can arrive. Embracing this notion of safety in all its many dimensions is what recovery asks of our institutions of learning and research. Only if recovery is acknowledged as pertinent to institutional life, and the connection to reverie recognized and nurtured, will glimpses of new emotional, social, and political forms become available.

\section{Acknowledgments}

I am grateful to the Arts and Humanities Research Council (Connected Communities program, Artists Legacies project, PI Kate Pahl) and to the European Research Council (Knowing from the Inside project, PI Tim Ingold), who supported the research into drawing; to the Arts and Humanities Research Council (Connected Communities program), for follow-on funding for Wonderland; and to all my fellow researchers and recoverists who so generously gave their experience and time. Thanks to Clive Parkinson and Rachel Genn, who read and commented on an earlier draft of this essay. Special thanks to Alison Brown, of the Department of Social Anthropology, Aberdeen University, who helped me to see what I had made through her reading of an earlier version of this essay for the workshop on collaboration organized there by Caroline Gatt in 2016 and to Caroline herself for her invaluable input.

AMANDA RAVETZ is a professor of visual and social practice at Manchester Metropolitan University. Her research interests involve art and visible recovery, experiences of reverie in artistic and psychoanalytic practice, and models of validation for social practice. Recent publications include Collaboration through Craft, co-edited with Alice Kettle and Helen Felcey (2013, Bloomsbury Academic); "The Ethnographic Turn-and After: A Critical Approach to the Re-alignment of Art and Anthropology" (with Anna Grimshaw), in Social Anthropology, 23, no. 4 (2015): 1-17; Wonderland: the art of becoming human, winner of the Utopia category, AHRC Research in Film Award 2016; "The Night Manifesto," in Associations: Creative Practice and Research, ed. James Oliver (Melbourne University Press, 2018); and "Black Gold: 
1. "Without Memory of Desire," in The Clinical Thinking of Wilfred Bion by Joan and Neville Symington (London: Routledge, 1996), 169.

2. This is one of the most difficult aspects of reverie to bring into understanding and one of the most interesting: in my experience of reverie it seems to transform the sensory rather than completely escape it; this provides interesting nuance to the recent sensory turn in anthropology, also referenced in art and design.

3. In psychoanalysis, reverie is theorized as an inherently intersubjective state. It is typified by the daydreaming enacted by the primary carer-infant pair, where the carer "contains" and digests the infant's raw sense data.

4. The art critic Adrian Stokes extends this idea to the audience of artworks, suggesting that in a successful work there is little to differentiate the artist's experience of making work and the audience's reception of it: the "deep grammar" of a successful painting or sculpture bears traces of the necessary working through of psychic pain and frustration, transformed in the final piece into "something sane." See Meg Harris Williams, ed., Art and Analysis: An Adrian Stokes Reader (London: Karnac, 2014).

5. Here I follow the reasoning of anthropologists such as Kay Milton (2002) and Tim Ingold (2000) that social and ecological relations are one in the same thing.

6. This was during Connecting Art and Anthropology, a workshop I organized in 2007 to bring art and anthropology together. See http://www.miriad.mmu.ac.uk/caa /index.php.

7. I use the term things in themselves (and noumenon, and $O$ ) to describe the results of what feels like a shift away from my established "center of perception." While I recognize that these terms originate in philosophical positions that rely on boundaries between, for example, ecological and social relations, noumena and phenomena, I have allowed myself this apparent paradox because the phrase things in themselves describes so well an experience in which phenomena appear to take on an awe-inspiring and independent existence not usually discerned by everyday perception.

8. http://compaso.eu/wp-content/uploads/2015/02/Compaso2014-52-Ravetz.pdf.

9. http://www.criticalimprov.com/article/view/2139/2940.

10. This was part of the AHRC-funded project "Co-producing Legacy: What Is the Role of Artists within Connected Communities Projects?” PI Kate Pahl.

11. We drew and talked for three days and then "wrote up" our experiences, focusing on what we described as "8 hunches." Our starting hypothesis was of drawing as "inherently collaborative, between individuals, and between an individual and an emergent world that is always in formation" (Douglas et al. 2014). Reverie was not an explicit part of the AHRC agenda, but it was something we discussed at length within this smaller team.

12. Journal of Arts and Communities 6, nos. 2-3 (2014).

13. According to Crow and Mah the qualities commonly associated with community 
15. Mark Prest, director of PORe-Portraits of Recovery, is a visual arts charity bringing together contemporary artists with people and communities affected by addiction and recovery to break down barriers and give a human face to recovery. See https:// portraitsofrecovery.org.uk/.

16. The website for the project can be seen at http://www.art.mmu.ac.uk/wonderland/.

17. Partners were Portraits of Recovery, Greater Manchester Recovery Foundation, and inzrecovery. The research was funded by the AHRC as part of the Utopia Festival 2016.

18. See https://cristinanunez.com/the-self-portrait-experiencel/.

19. For example, they collected family photos where these were available and made portraits of themselves, important places, and other people. They also met in an ongoing peer-led support group.

20. https://issuu.com/artsforhealth/docs/rm_online_version.

21. Rouch's work on cine-transe in cinema and Bion's on "work-group mentality" could be used to theorize this further.

22. These sessions were also called Wonderland: the art of becoming human. https:// vimeo.com/171903022.

23. This powerful and intriguing comment mirrors Bion's concept of "the language of achievement," cited by Grotstein $(2007,15)$ in what Grotstein describes as the "primal language of emotions."

24. "The books were beautiful, some really raw and brutal, others quite poetic-some of the portraits reminded me of traditional, art historical styles-the dark backgrounds like Velazquez, the lady with long red hair, very Pre-Raphaelite. When reading the books, I almost felt like I was imposing or entering very personal spaces, and at times this made me feel rather uncomfortable. I don't view this as a bad aspect, I wonder if in some ways they are meant to be slightly confrontational and honest. Were the photobooks meant to be viewed outside the group? Were the participants carrying out research into artists' books?" Gemma Meek, PGR student.

25. http://alcoholrehab.com/addiction-recovery/the-importance-of-gratitude-in -recovery/.

26. Defined by Krieger as one in which "specific features of and pathways by which societal conditions affect health and that potentially can be altered by informed action" (Krieger 2001, 697).

27. See review by Dan L. Rose of The Psychoanalytic Mystic by Michael Eigen in Metapyschology Online reviews, February 15, 2000 (vol. 4, no. 7), http://metapsychology .mentalhelp.net/poc/view_doc.php?type=book\&id=224.

28. See note 7 on my use of these terms.

29. $O$ is explained further by the Symingtons $(1996,122)$ as "an ultimate reality which cannot be known but can only be 'become,' that is, it is possible to be at one with it."

\section{References}

Crow, G. and A. Mah. 2011. Conceptualisations and Meanings of Community: The Theory and Operationalization of a Contested Concept. Project report. http://www.ahrc.ac.uk/documents/project-reports-and-reviews/connected -communities/conceptualisations-and-meanings-of-community-the-theory-and -operationalization-of-a-contested-concept/. 
Douglas, A., A. Ravetz, K. Genever and Johan Siebers. 2014. "Why Drawing, Now?"

Journal of Arts and Communities 6, nos. 2-3. Bristol: Intellect Books.

Ehrenreich, Barbara. 2014. Living With a Wild God. London: Granta Books.

Friedli, Lynne. 2013. "What we've tried, hasn't worked: The Politics of Assets Based Public Health." Critical Public Health 23, no. 2.

Grotstein, James. 2007. A Beam of Intense Darkness: Wilfred Bion's Legacy to Psychoanalysis. London: Karnac.

Harris Williams, Meg, ed. 2014. Art and Analysis: An Adrian Stokes Reader. London: Karnac.

Ingold, Tim. 2000. The Perception of the Environment. London: Routledge.

Kimmerer, Robin Wall. 2013. Braiding Sweetgrass, Minneapolis: Milkweed Productions.

Krieger, N. 2001. "A Glossary for Social Epidemiology." J. Epidemiol. Community Health 55, no. 10: 693-700.

Milner, Marion. 1938. The Human Problem in Schools: A Psychological Study Carried Out on Behalf of the Girls' Public Day School Trust. Contributions to Modern Education. London: Methuen.

- [Joanna Field]. 1957 [1950]. On Not Being Able to Paint. 2nd edition. London: Heinemann.

- 1987. The Suppressed Madness of Sane Men. London: Routledge.

Milton, Kay. 2002. Loving Nature: Towards an Ecology of Emotion. London: Routledge.

Nancy, Jean-Luc. 1991. The Inoperative Community. Ed. Peter Connor, trans. Peter Connor, Lisa Garbus, Michael Holland, and Simona Sahey. Minneapolis: University of Minnesota Press.

- 2013. The Pleasure in Drawing. Trans. Phillip Armstrong. New York: Fordham University Press.

Pahl, Kate, H. Escott, H. Graham, K. Marwood, S. Pool, and A. Ravetz. 2017. "What Is the Role of Artists in Interdisciplinary Collaborative Projects with Universities and Communities?" In Valuing Interdisciplinary Collaborative Research: Beyond Impact, ed. Ken Facer and Kate Pahl, 131-52. Bristol: Policy Press.

Pietro, C., S. Silvia, and R. Giuseppe. 2014. "The Pursuit of Happiness Measurement: A Psychometric Model Based on Psychophysiological Correlates." Scientific World Journal, 139128. http://doi.org/10.1155/2014/139128.

Raikhel, Eugene, and William Garriot, eds. 2013. Addiction Trajectories. Durham, NC:

Symington, Joan, and Neville Symington. 1996. "Without Memory of Desire." In The Clinical Thinking of Wilfred Bion, 169. London: Routledge.

\section{Websites}

Connecting Art and Anthropology, http://www.miriad.mmu.ac.uk/caa/index.php. 